\title{
Prevalensi Dan Faktor-Faktor Penyebab Musculoskeletal Disorders Pada Operator Gudang Industri Ban PT X Tangerang Indonesia
}

\author{
Chindy Elsanna Revadi ${ }^{1}$, Cahya Surya Gunawan ${ }^{2}$, Galih Jaler Rakasiwi ${ }^{3}$ \\ ${ }^{1,2,3)}$ Teknologi Industri, Politeknik Gajah Tunggal \\ chindyrevadi@gmail.com,gunawantedjomulyo@gmail.com,galihjaler7@gmail.com \\ doi: https://doi.org/10.24843/JEI.2019.v05.i01.p02 \\ Article Received: 28 Mei 2019; Accepted: 7 Juni 2019; Published: 30 Juni 2019
}

\begin{abstract}
Abstrak
Musculoskeletal disorders yang merupakan gangguan pada otot rangka dapat menurunkan produktivitas terutama pada operator gudang industri ban. Penelitian ini bertujuan untuk mengetahui prevalensi dan faktor-faktor yang meningkatkan musculoskeletal disorders pada operator gudang industri ban PT X. Tiga puluh orang partisipan operator gudang ban mengikuti penelitian ini dengan mengisi kuesioner Nordic Body Map atau instrumen keluhan otot rangka. Hasil penelitian menunjukkan bahwa tingkat musculoskeletal disorders tertinggi pada operator gudang ban PT X terjadi di bagian punggung bawah. Faktor-faktor yang berpengaruh terhadap risiko musculoskeletal disorders pada operator gudang ban PT X adalah usia, berat badan, pendidikan terakhir dan lama bekerja untuk bagian tubuh punggung bawah, lutut dan pergelangan kaki. Untuk mengurangi risiko musculoskeletal disorders perlu dilakukan pengawasan postur kerja dan perancangan lingkungan kerja yang melibatkan seluruh anggota perusahaan.
\end{abstract}

Kata kunci: musculoskeletal disorder, gudang, Nordic Body Map, postur kerja.

\section{Prevalence And Factors Causing Musculoskeletal Disorders At the Operator of Tire Industry Warehouse PT X Tangerang, Indonesia}

\begin{abstract}
Musculoskeletal disorders which are an injury or pain in the human musculoskeletal system can reduce productivity especially the warehouse workers at a tire industry. This research aims to observe the prevalence and the factors which increase the musculoskeletal disorders among the warehouse workers at a tire industry. Thirty warehouse workers of a tire warehouse participated in this study by filling out a Nordic Body Map questionnaire or skeletal muscle complaints instrument. The result of this study showed that the highest prevalence of the musculoskeletal disorders at the warehouse workers at a tire industry occurred at the lower back area. The factors which influence the risk of musculoskeletal disorders of the warehouse workers at the tire industry are age, weight, educational background, and the duration of working by using the lower back, knees, and ankles. To reduce the risk of musculoskeletal disorders, it is necessary to supervise the work posture and design a work environment which involves all members of the company.
\end{abstract}

Keywords: musculoskeletal disorder, warehouse, Nordic Body Map, work posture.

\section{PENDAHULUAN}


Dalam menghadapi persaingan industri, suatu perusahaan dituntut untuk dapat meningkatkan produktivitas. Salah satu faktor yang dapat menurunkan produktivitas adalah terjadinya musculoskeletal disorders (Podniece, dkk., 2008). Musculoskeletal disorders (MSDs) merupakan gangguan yang mempengaruhi pergerakan tubuh atau sistem otot rangka manusia (Kroemer dan Grandjean, 1997). Berdasarkan laporan statistik Human Safety and Work (2018) di Inggris terdapat 500.000 kasus munculnya musculoskeletal disorders sepanjang periode 2017. Sementara itu, penelitian terkait musculoskeletal disorders juga telah dilakukan pada berbagai sektor industri manufaktur dan jasa di Indonesia (Rahayuningsih, dkk., 2018).

PT X merupakan salah satu perusahaan yang bergerak dalam industri manufaktur ban yang berlokasi di Tangerang, Indonesia. Industri manufaktur ban termasuk dalam kelompok industri dengan bahan karet dimana terdapat berbagai proses produksi yang dapat menimbulkan risiko terjadinya musculoskeletal disorders (Samei, dkk., 2017). Salah satu penyebab musculoskeletal disorders pada industri ban diakibatkan oleh postur kerja yang salah, penanganan barang berat, dan bekerja pada posisi berdiri dalam waktu yang lama (Choobineh, dkk., 2007). Aktivitas penanganan barang berat berupa ban yang dilakukan pada PT X, sebagian besar dilakukan pada departemen gudang. Postur tubuh operator gudang yang tidak tepat saat mengangkat, mendorong serta menarik benda berat saat proses bongkar muat juga dapat menimbulkan rasa sakit punggung dan lengan sebagai bagian dari musculoskeletal disorders (Basahel, 2015). Selain postur tubuh operator yang tidak tepat, musculoskeletal disorders juga dipengaruhi oleh level pendidikan, usia, masa kerja serta pengalaman bekerja. Perbedaan usia dan masa kerja operator dapat menunjukkan perbedaan posisi bagian tubuh yang mengalami musculoskeletal disorder (Choobineh, dkk., 2007; Ramdan, dkk., 2018).

Proses penanganan masalah musculoskeletal disorders diawali dengan penilaian ergonomi dari beberapa aspek (Thetkathuek, dkk., 2016). Dalam penelitian ini penilaian ergonomi dilakukan dengan menggunakan kuesioner Nordic Body Map menurut Kuorinka dkk. (1987) yang telah diterjemahkan dalam Bahasa Indonesia oleh Widanarko dkk. (2016). Hasil dari penelitian ini menyajikan prevalensi musculoskeletal disorders pada operator gudang industri ban. Selain itu hasil penelitian juga dapat digunakan sebagai dasar pertimbangan dalam merancang intervensi ergonomi untuk menurunkan risiko musculoskeletal disorders pada operator gudang secara umum.

\section{METODE}

Dalam penelitian ini dilakukan identifikasi musculoskeletal disorders pada operator bongkar muat gudang ban PT X yang terdiri dari 30 (tiga puluh) orang. Instrumen penelitian yang digunakan adalah kuesioner survei gangguan otot rangka yang disusun oleh Widanarko dkk. (2016). Instrumen tersebut terdiri dari pertanyaan mengenai data demografi partisipan serta pertanyaan terkait waktu mengalami keluhan gangguan otot rangka, gangguan dalam beraktivitas, apakah partisipan menemui dokter atau terapis saat mengalami gangguan otot rangka, dan tingkat masalah otot rangka yang dirasakan partisipan.

\section{HASIL DAN PEMBAHASAN}

Hasil pengumpulan data pada penelitian ini telah disusun dalam dua kelompok yaitu data demografi serta data keluhan otot rangka. Partisipan dalam penelitian ini terdiri dari 30 (tiga puluh) orang operator bongkar muat dari tiga departemen gudang ban PT X. Gambaran aktivitas partisipan disajikan pada Gambar 1 berikut dimana dapat diketahui bahwa partisipan bekerja secara manual dalam mengangkat beban berat. 


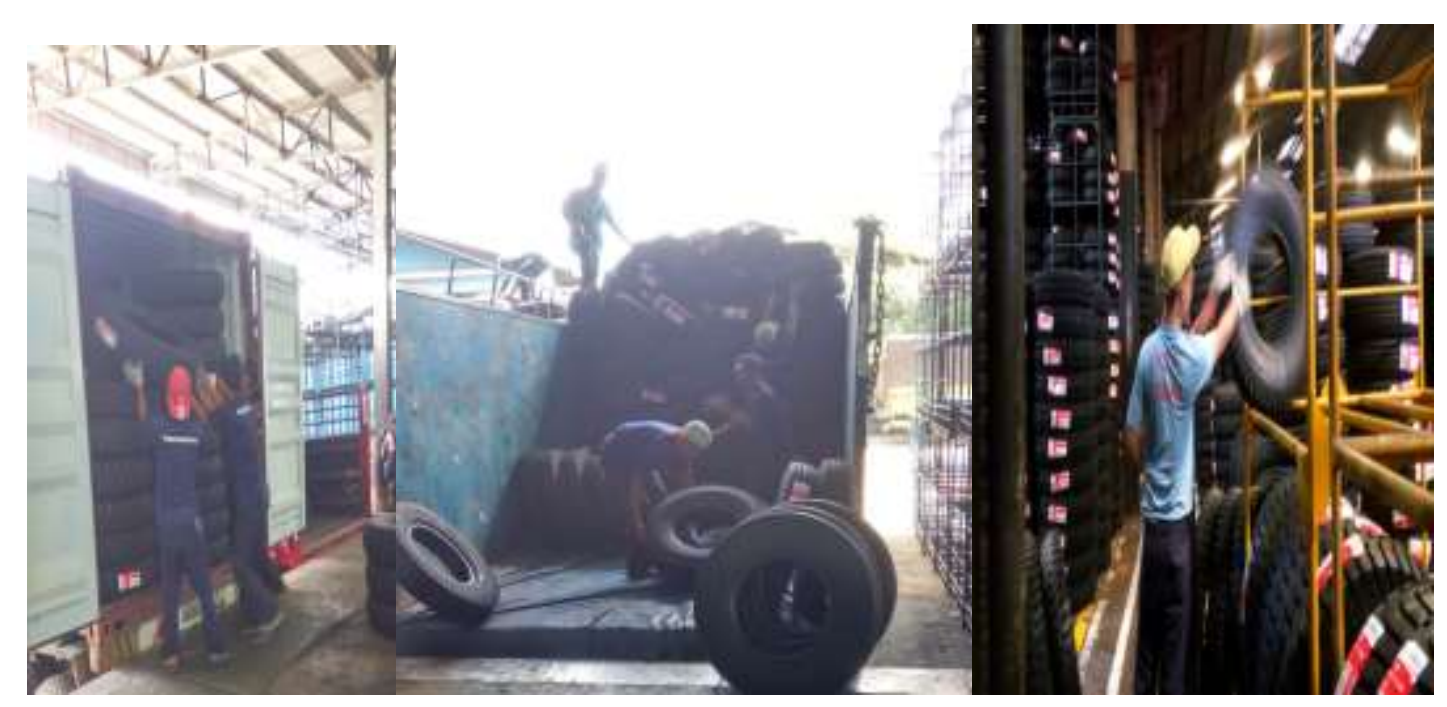

Gambar 1. Operator Bongkar Muat Gudang Ban PT X

Seluruh partisipan dalam penelitian ini berjenis kelamin laki-laki dan bekerja selama 8 (delapan) jam sehari tanpa shift. Adapun rangkuman nilai rata-rata data demografi disajikan pada Tabel 1 berikut.

Tabel 1.

Data Demografis Partisipan

\begin{tabular}{lc}
\hline \multicolumn{1}{c}{ Uraian } & Rerata \\
\hline Usia (tahun) & 40,87 \\
Tinggi badan $(\mathrm{cm})$ & 166,83 \\
Berat badan $(\mathrm{kg})$ & 63,9 \\
Pendidikan Terakhir & \\
SD & 9 orang \\
SMP & 7 orang \\
SMA & 14 orang \\
Lama bekerja (tahun) & 17,34 \\
\hline
\end{tabular}

Selanjutnya disajikan rangkuman data rerata penilaian masalah (sakit, nyeri dan tidak nyaman) pada otot rangka sesuai masing-masing bagian tubuh dengan skala 1-10. Menurut Tabel 2 dapat diketahui bahwa seluruh partisipan mengalami permasalahan pada bagian punggung bawah dengan rata-rata nilai sakit atau nyeri tertinggi dalam 12 (dua belas) bulan terakhir. Hal tersebut sesuai dengan pernyataan Motamedzade (2013), Basahel (2015) dan Samei dkk. (2017), bahwa operator yang bekerja pada gudang terutama industri yang berkaitan dengan karet atau ban sering mengalami keluhan pada bagian punggung bawah yang disebabkan proses pengangkatan benda berat. Seluruh partisipan dalam penelitian ini juga menyatakan bahwa gangguan otot rangka pada bagian punggung bawah menghambat aktivitas saat bekerja, walaupun hanya $2 \%$ partisipan melakukan konsultasi kepada dokter atau terapis terkait masalah tersebut.

Untuk mengetahui hubungan antara penilaian masalah dengan data demografis dilakukan uji analisis regresi dengan menggunakan aplikasi SPSS 25. Berdasarkan hasi uji regresi dapat diketahui bahwa terdapat perbedaan usia, tinggi badan, berat badan, pendidikan terakhir, dan lama bekerja menunjukkan perbedaan tingkat masalah (nyeri/sakit) pada bagian 
punggung bawah operator gudang dengan nilai signifikansi dibawah 0,05 yaitu 0,$000 ; 0,000$; dan 0,017 .

Tabel 2.

Data Penilaian Rasa Sakit/Nyeri Otot Rangka

\begin{tabular}{lcccc}
\hline \multicolumn{1}{c}{ Bagian tubuh } & $\begin{array}{c}\text { Partisipan yang } \\
\text { mengalami } \\
\text { masalah rangka } \\
\text { otot }(\%)\end{array}$ & $\begin{array}{c}\text { Rerata } \\
\text { penilaian rasa } \\
\text { sakit/nyeri }\end{array}$ & $\begin{array}{c}\text { Partisipan yang } \\
\text { mengalami } \\
\text { gangguan dalam } \\
\text { beraktivitas }(\%)\end{array}$ & $\begin{array}{c}\text { Partisipan yang } \\
\text { mengalami menemui } \\
\text { dokter atau terapis } \\
(\%)\end{array}$ \\
\hline Leher & 80 & 3,57 & 20 & 0 \\
Bahu & 83 & 4,10 & 24 & 0 \\
Punggung atas & 9 & 3,93 & 25 & 0 \\
Siku & 73 & 3,36 & 15 & 0 \\
Punggung Bawah & 100 & 6,36 & 100 & 2 \\
Pergelangan Tangan & 90 & 3,90 & 30 & 0 \\
Bokong/Paha & 83 & 3,90 & 38 & 0 \\
Lutut & 86 & 4,60 & 35 & 0 \\
Pergelangan Kaki & 86 & 4,20 & 29 & 0 \\
\hline
\end{tabular}

Perbedaan berat badan dan lama bekerja juga menunjukkan perbedaan tingkat masalah pada bagian lutut operator gudang dengan nilai signifikansi 0,040. Sementara untuk bagian pergelangan kaki operator gudang mengalami perbedaan tingkat masalah yang disebabkan oleh perbedaan lama bekerja dengan nilai signifikansi 0,030.

Menurut Thetkathuek dkk. (2016) pada rentang usia 35-55 tahun permasalahan nyeri/sakit yang disebabkan oleh musculoskeletal disorders meningkat hingga $70 \%$. Usia dan berat badan yang mempengaruhi kekuatan masa otot juga dapat menunjukkan perbedaan pada tingkat risiko musculoskeletal disorders (Samei, dkk., 2017). Sementara itu, latar belakang pendidikan dan lama bekerja diikuti dengan peningkatan cara berpikir yang rasional sehingga lebih mudah dalam menerapkan pengetahuan atau aturan yang mencegah terjadinya musculoskeletal disorders (Ramdan, dkk., 2018).

Penanganan musculoskeletal disorders pada operator gudang dapat dilakukan dengan melakukan investigasi lebih lanjut serta peningkatan dalam pengawasan postur kerja (Kamat, dkk., 2017). Menurut Basahel (2015), postur saat mengangkat beban berat lebih berisiko menimbulkan musculoskeletal disorders dibandingkan aktivitas mendorong. Choobineh dkk. (2007), menyusun lima solusi utama dalam mencegah musculoskeletal disorders pada industri ban yaitu: mengurangi beban angkut secara manual, mengurangi tinggi rak untuk peletakan ban, menggunakan permesinan dalam mengangkat ban, merancang workstation yang sesuai dengan antropometri operator, serta menerapkan siklus jam istirahat berdasarkan kebutuhan operator. Dalam Motamedzade (2013), untuk mengurangi musculoskeletal disorders pada industri ban perlu dilakukan penerapan practical ergonomic dimana melibatkan seluruh anggota perusahaan untuk mengawasi kondisi lingkungan kerja. Kondisi menunjukkan sikap tubuh yang tidak ergonomis dalam angkat angkut seperti pada operator ban menimbulkan keluhan musculoskeletal pada berbagai lokasi terutama pinggang bawah, sehingga perlu dicarikan upaya perbaikan kondisi kerja yang ada.

Adapun keterbatasan dari penelitian ini adalah dalam pemilihan partisipan yang belum tentu dapat mewakili seluruh populasi untuk operator gudang pada industri ban. Jenis kelamin partispan dalam penelitian ini hanya laki-laki sehingga tidak dapat diketahui apakah perbedaan jenis kelamin dapat mempengaruhi terjadinya musculoskeletal disorder. Penelitian lebih lanjut juga perlu dilakukan untuk mengetahui pengaruh perbedaan data 
demografis terhadap musculoskeletal disorders pada bagian tubuh selain punggung bawah, lutut dan pergelangan kaki pada operator gudang ban.

\section{SIMPULAN}

Berdasarkan penelitian ini dapat diketahui bahwa tingkat dan persentase musculoskeletal disorders operator gudang ban PT X terjadi pada bagian punggung bawah. Faktor usia, berat badan, pendidikan terakhir dan lama bekerja menunjukkan pengaruh terhadap musculoskeletal disorders pada punggung bawah, lutut, dan pergelangan kaki operator gudang ban PT X. Hal tersebut dikarenakan perbedaan usia dan berat badan mempengaruhi kekuatan otot dalam mengangkat beban berat. Sementara pendidikan terakhir dan lama bekerja dapat menentukan cara berpikir dan menerapkan pengetahuan dalam mencegah terjadinya musculoskeletal disorder.

Untuk mengurangi risiko musculoskeletal disorders dapat dilakukan dengan melakukan pengawasan postur kerja dan lingkungan kerja serta perancangan alat maupun stasiun kerja yang sesuai dengan antropometri operator gudang. Saran yang dapat diberikan untuk penelitian selanjutnya yaitu dilakukan pemilihan partisipan dengan jumlah dan komposisi jenis kelamin yang lebih dapat mewakili seluruh populasi operator gudang ban. Selain itu juga perlu dilakukan pengkajian lebih lanjut untuk mengetahui pengaruh perbedaan data demografis terhadap musculoskeletal disorders pada bagian tubuh operator ban bagian atas.

\section{DAFTAR PUSTAKA}

Basahel, A. M. 2015. Investigation of work-related Musculoskeletal Disorders (MSDs) in warehouse workers in Saudi Arabia. Procedia Manufacturing, Vol 3:4643-4649.

Choobineh, A., Tabatabaei, S. H., Mokhtarzadeh, A., dan Saleh, M. 2007. Musculoskeletal Problem Among Workers of an Iranian Rubber Factory. Journal Occup Health, Vol 49:418-423.

Health and Safety at Work. 2018. Summary Statistics for Great Britain. London: National Statistics.

Kamat, S. R., Zula, N. E. N. MD., Rayme, N. S., Shamsuddin, S., dan Husain., K. 2017. The Ergonomic Body Posture on Repetitive and Heavy Lifting Activities of Workers in Aerospace Manufacturing Warehouse. IOP Conference Series: Materials Science and Engineering, Vol 1:210(1-13).

Kroemer K.H.E., dan E. Grandjean. 1997. Fitting the Task to the Human Textbook of Occupational Ergonomics. London: Taylor and Francis Ltd.

Kuorinka, I., Jonsson B., Kilbom A., Vinterberg, H., Sorensen, B.F., Anderson G., dan Jogersen K. 1987. Standardised Nordic Questionnaires for The Analysis of Musculoskeletal Symptoms. Appl Ergon, Vol. 18(3):233-237.

Motamedzade, M. 2013. Ergonomics Intervention in an Iranian Tire Manufacturing Industry. International Journal of Occupational Safety and Ergonomics, Vol. 19(3):475-484.

Podniece Z, Heuvel S, Blatter B. 2008. Work-related Musculoskeletal Disorders: Prevention Report. European Agency for Safety and Health at Work. Spain: EU Publication.

Rahayuningsih, S., Widyanti, A., Indrasari, L.D., dan Soetisna, H. R. 2018. Prevalence of Musculoskeletal Symptoms/Disorders in Tofu Industries in Kediri. AIP Conference Proceedings. 0200271-020027-4.

Ramdan, I. M., Candra, K. P., dan Fitri A., R. 2018. Affecting Musculoskeletal disorders (MSD) Prevalence among Women Weavers Working With Handlooms in Samarinda, Indonesia. International Journal of Occupational Safety and Ergonomics, Vol. 1:23769130. 
Samei, S. E., Tigar, A., Khanjani, N., Mostafaee, M., dan Hosseninabadi, M. B. 2017. Effect of Personal Risk Factors on The Prevalence Rate of Musculoskeletal Disorders Among Workers of an Iranian Rubber Factory. Work, Vol. 57:547-553.

Thetkathuek, A., Meepradit, P., dan Jaid W. 2016. Factors Affecting the Musculoskeletal Disorders of Workers in The Frozen Food Manufacturing Factories in Thailand. International Journal of Occupational Safety and Ergonomics, Vol 22(1):49-56.

Widanarko, B., Kusmasari W., Yassierli., dan Iridiastadi, H., 2016. Instrumen Survey Gangguan Otot Rangka. Jakarta: Perhimpunan Ergonomi Indonesia 